\title{
Javier de NAvascués. Alpargatas contra libros: el escritor y las masas en la literatura del primer peronismo (1945-1955). Madrid/Frankfurt: Iberoamericana/Vervuert, 2017.
}

Empezando por un título sagaz que lleva al lector in medias res a la Argentina de los ańos cuarenta del siglo $\mathrm{xx}$, Javier de Navascués presenta un trabajo completo y exhaustivo sobre los conceptos de escritor y masa durante los primeros ańos del peronismo. Con una perspectiva clara y concisa, estructura el libro de manera coherente, investigando minuciosamente la definición de «masa» y planteando su relación con la élite intelectual, situando su estudio en el contexto histórico de los primeros años del gobierno de Perón, entre 1945 a 1955.

La monografía se adentra en el complejo mundo de esa masa, delineando sus facetas primordiales, relacionadas con los sentimientos del miedo y de la ilusión. Se centra en "ka invasión como relato», tomando en consideración a los grandes nombres de la literatura argentina, como Borges, Cortázar, Bioy Casares, Martínez Estrada y Leopoldo Marechal. El ensayo empieza con una pregunta fundamental: "¿Hasta qué punto se asumen las conquistas de la colectividad?» (13). Es un dilema esencial, ya que los intelectuales de la época, por un lado, sienten la presión del compromiso que los liga a la sociedad $y$, por otro lado, siguen encontrando limitaciones que no saben gestionar. Es por esta misma razón que el autor dedica el libro a las relaciones entre el intelectual y la sociedad en Argentina a través de su literatura, teniendo muy en cuenta el contexto histórico en el que se desarrollan dichas relaciones. Empezando por la descripción del panorama literario argentino en su periodo dorado, durante la década de los ańos 40, el autor desliza poco a poco su enfoque hacia el ascenso de Perón.

El escenario, en síntesis, es Argentina y las luces iluminan a dos de sus protagonistas: por un lado, la "masa»: un término que desde el siglo XIX tenía un significado despectivo, como si fuese un sinónimo de la palabra «plebe» en su más aviesa acepción. Por otro lado, el intelectual de los ańos cuarenta: una figura que desea verse privilegiada. El objetivo de este estudio es la comprensión de la relación entre los dos durante el primer periodo del peronismo, y distingue tres partes esenciales. En la primera se centra en el término de «masa» y en los productos culturales generados por Perón, quien no solo introduce reformas sociales fundamentales, sino que también consigue atraer a la multitud con su carisma. La segunda parte se dedica al estudio de las representaciones literarias de aquel periodo centrándose en la manifestación del 17 de octubre de 1945, el mito fundacional del peronismo por antonomasia, y en último lugar el autor realiza un análisis textual de escritores representativos del periodo 45-55. Los textos tomados en consideración por Navascués oscilan entre el análisis de obras de escritores conservadores y de izquierda, teniendo siempre en cuenta la masa como invasora feroz del espacio público. Uno de los casos más interesantes es, sin duda, el de la poetisa Delfina Bunge y su marido Manuel Gálvez: tras un primer periodo en el que parecen apoyar el peronismo, viéndolo afín a su fe católica, terminan escribiendo unos textos abiertamente antiperonistas, como El uno y la multitud y Tránsito Gúzman. La razón reside en las discrepancias que habían ido surgiendo entre el gobierno y los entes católicos conforme el peronismo iba avanzando. A pesar de sus divergencias con la religión, en el panorama literario la figura de Perón seguía siendo tachada de Mussoliniana, y subrayaba además «el abismo existente entre los escritores de la alta cultura y de realidad cotidiana de la Argentina» (67). A pesar de que solo algunos rasgos de la política de Perón pertenecieran al fascismo, Borges lo veía como a un "Mussolini Criollo» (51) exaltador de las masas y recreador de un teatro junto a sus prosélitos. La acepción de teatro no es casual, ya que Perón consigue construir un mundo de falsedad y mentiras, que Borges querrá desafiar a duelo representando esta "Comedia» junto a Bioy Casares en el libro $L a$ fiesta del Monstruo, obra menor para ambos autores, pero fundamental en la literatura antiperonista. En 
la obra se delinea el estado animalesco y carnavalesco de la masa: los personajes que forman parte de esta muchedumbre son incultos, salvajes y están perfectamente representados por un lenguaje con «numerosas referencias animales» (119).

El ambiente descrito tiene evidentemente el objetivo de privar de humanidad e inteligencia a los secuaces de Perón. Uno de ellos, por ejemplo, se merece el epíteto de "Graffiacane», uno de los diablos del canto XXI de la Divina Commedia de Dante, y cuyo nombre remite a la idea de un perro con largas garras. La idea de denuncia se ve expresada por más autores, como Beatriz Guido en El incendio y las visperas, que quiere darle un tono testimonial enfocándose sobre acontecimientos reales, como por ejemplo la apropiación de los espacios privados como si fueran públicos, o los incendios en lugares cruciales para el gobierno. La idea carnavalesca y teatrera de la masa está compartida también por María Rosa Oliver, que Navascués incluye en las filas izquierdistas del periodo. Se ponen de relieve sin embargo las partes paradójicas de su discurso, ya que «la misma narradora que vibra con las masivas reivindicaciones en España o Rusia es la que juzga con incredulidad la primera gran manifestación obrera a la que asiste en su propio país, la del 17 de octubre» (143).

Cortázar en cambio propone un nuevo paradigma interpretativo enfocándose sobre «lo no dicho», como en el caso del cuento "Casa tomada», donde se centra en la «invasión multitudinaria del peronismo en todos los ámbitos de la vida cotidiana» (148). Navascués indica como totalmente comprensible la voluntad de Cortázar de optar por lo no dicho, evitando la denuncia directa de Borges y Bioy Casares. Esto no quita en todo caso la preocupación del joven escritor, expresada del mismo modo en la que él percibía el peronismo: de manera «indecible por monstruosa, mezclada, confusa» (158). Elige por lo tanto nombrar al peronismo sin nombrarlo, un procedimiento que será fundamental y que creerá un nuevo paradigma que será usado por muchos otros escritores argentinos, fundando además nuevo espacio literarios donde los protagonistas serán siempre los invasores y los invadidos, y cuyas características irán cambiando dependiendo del desarrollo de la vida política argentina.

Por último, el autor se centra sobre la figura controvertida de Leopoldo Marechal. En principio gran amigo de Borges, se convierte en sostenedor de Perón el mismo 17 de octubre, «entusiasmado por el espectáculo de la masa» (83). Director de Cultura desde el año 1945 pasa a un puesto de menor jerarquía: la Dirección de Enseñanza Superior y Artística. Se le niegan los ascensos reservados a otros, que solo tenían relevancia en el ámbito político, condenándolo así a ser un enamorado no correspondido. De hecho, el peronismo nunca se sirve de la literatura de Marechal a pesar de su devoción al partido, pues el objetivo era en este caso un contacto directo líderpueblo. Se explica así según Navascués: «la sensación de aislamiento que transmite la última novela de Marechal, quien escenifica en su héroe el drama del intelectual peronista que desea aportar a la causa el poder de una palabra que su misma revolución no está interesada en promover» (216). Su entusiasmo político le cuesta además el reconocimiento de la élite intelectual de la época, que lo segrega del canon y de la vida intelectual.

A pesar de las diferencias políticas entre BorgesMarechal, que se toman aquí como ejemplo de dos grandes polos opuestos en el primer peronismo, Navascués se plantea la cuestión sobre las posibles distancias entre los dos. Se revelan a este punto unas líneas que acomunan ambos escritores, como por ejemplo la herencia de la tradición occidental, los dos dan espacio a elementos que forman parte del genero popular y ninguno de los dos eran extremistas, pues como indica el autor: «Ni Marechal es un nacionalista cerrado, ni Borges un escritor despreocupado de la cultura popular» (217). Otro punto en común es la imagen dantesca de la mujer que Marechal propone en Adán Buenosayeres y Borges en El Aleph.

De esencial importancia es la escena de Adán Buenosayres, en la que «el pesado Rivera se acerca a Samuel Tesler perjudicado por el alcohol y le sacude un zapatillazo en la cabeza. Este brote inesperado de violencia sirve de catarsis para que se recupere la cordialidad entre todos. Es un golpe simbólico, como si la alpargata popular propinara un aviso en la mente libresca del intelectual, todo contado en un tono zumbón» (217).

A partir de aquí, el lector soluciona la interrogación atávica que ha impregnado todo el libro: ¿Alpargatas o libros? Para ello, Javier de Navascués ofrece los instrumentos para contestar a esta pregunta: la verdadera cuestión reside en la lucha del individuo-intelectual contra la masa. El ensayo resuelve de manera excelente la dialéctica entre la masa y el individuo y los pone en relación a través de un estudio riguroso de las obras y de los distinguidos intelectuales argentinos del primer peronismo.

Elisa Munizza Universidad de Alicante 